\title{
Requisitos para a criação de um equipamento para movimentar e transferir pessoas com mobilidade reduzida no leito
}

Requirements for the creation of an equipment to move and transfer persons with reduced mobility in bed

ALVES, Marcelo; Mestre; Univille

marcelo.alves2702@gmail.com

CAVALCANTI, Anna; Mestre; Univille

anna.cavalcanti08@gmail.com

\section{Resumo}

Este artigo é um recorte da pesquisa empreendida no Mestrado em Design da Univille. A metodologia de pesquisa utilizada foi a revisão bibliográfica sobre os problemas da mobilidade reduzida, sobretudo causada pelo envelhecimento, e os desafios dos cuidados familiares e profissionais pela falta de equipamentos adequados. A abordagem metodológica projetual foi o Design Thinking, que contempla as etapas de Empatia, Definição, Criação, Prototipagem e Teste. 0 presente relato trata sobre as duas primeiras etapas: Empatia, com a pesquisa de campo nos lares de longa permanência para entendimento dos problemas in loco; e a etapa Definição, com a pesquisa desk e posterior análise e síntese dos dados em uma proposta de valor. Os resultados obtidos nestas duas etapas foram estruturados em uma lista de requisitos que orientou o desenvolvimento de um equipamento de movimentação e transferência de pessoas com mobilidade reduzida no leito. Esta pesquisa passou pelo comitê de ética e foi aprovada na Plataforma Brasil/CAAE: 42280115.2.0000.5366.

Palavras Chave: Design; Empatia; mobilidade e requisitos.

\begin{abstract}
This article is a part of the research undertaken in the Masters in <omitido para revisão cega>. The research methodology used was the bibliographical review on the problems of reduced mobility, mainly caused by aging, and the challenges of family and professional care due to the lack of adequate equipment. The design methodological approach was Design Thinking, which contemplates the stages of Empathy, Definition, Creation, Prototyping and Testing. The present report deals with the first two stages: Empathy, with field research in long-stay homes to understand problems in loco; and stage Definition in which the data were treated and synthesized in a value proposition and structured into a list of requirements for the development of equipment for movement and transfer of people with reduced mobility in the bed. This research passed the ethics committee and was approved in the Brazil Platform / CAAE: 42280115.2.0000.5366.
\end{abstract}

Keywords: Design; Empathy; mobility and requirements. 


\section{Contextualização}

Os problemas de mobilidade reduzida podem ser causados pela idade, por doenças degenerativas, por acidentes, dentre outros fatores, deixando a pessoa acamada ou dependente de ajuda. O estado de dependência pode afetar a autonomia para a realização das atividades da vida diária, tornando a pessoa incapaz de interagir com o seu contexto. Normalmente essa situação afeta o bem-estar e a qualidade de vida, gerando frustação e desconforto.

Pessoas com mobilidade reduzida tem dificuldades para sair de uma cadeira de rodas, da cama, ir ao banheiro ou executar qualquer atividade que envolva deambular pelo ambiente, especialmente sem assistência. Nesta condição destacam-se os idosos, os quais representam uma população crescente no Brasil, trazendo implicações para a sociedade que podem afetar os sistemas de cuidados, com o aumento do número total de casos de doenças crônicas e degenerativas, e consequentemente diminuição da capacidade funcional, tornando o idoso frágil, comprometendo sua mobilidade e capacidade de executar as atividades da vida diária, influenciando na sua qualidade de vida e bem-estar (CHRISTOPHE, 2007). De acordo com o documento Development in an Ageing World publicado pela Nações Unidas (UN), o ambiente social em que as pessoas envelhecem está mudando rapidamente, trazendo implicações importantes nos países desenvolvidos e em desenvolvimento. O tamanho das famílias está diminuindo, as percepções em relação ao apoio, carinho e as condições das pessoas mais velhas, vem se transformando. Nesse cenário, faz-se necessário a expansão do fornecimento de cuidados formais de longo prazo para as pessoas idosas, incluindo vida institucional (serviço formal), bem como os serviços alternativos para aqueles que desejarem ficar em suas casas (serviço informal).

o Brasil é um dos países em desenvolvimento em que o ritmo de envelhecimento é acelerado, haja vista que o estatuto do idoso foi implantado somente em 2003 sob a Lei 10.741/2003. Segundo o estatuto, uma pessoa é considerada idosa a partir de 60 anos de idade.

Em 2014, segundo o IBGE ${ }^{1}$, no Brasil o número de idosos era de 20,6 milhões, representando $10,8 \%$ da população total. Destes, $7,9 \%$ são pessoas com 65 anos ou mais e as projeções indicam que a estimativa de vida passará de 75 anos em 2013, para 81 em 2060.

Camarano e Kanso (2010) demonstram um cenário para 2020 em que 4,5 milhões de idosos terão dificuldades nas atividades da vida diária, e necessitarão de cuidados de longa duração. Este número é cerca de 1,3 milhão a mais comparado com 2008, e deste total, as mulheres representam cerca de $62,7 \%$.

A legislação brasileira estabelece que o cuidado dos idosos deva ser de responsabilidade das famílias, mas essa condição está se tornando escassa em função da redução da fecundidade, das mudanças na nupcialidade e da crescente participação da mulher no mercado de trabalho. A mulher é considerada tradicionalmente como a principal cuidadora (Camarano, 2010). Dessa maneira, a capacidade dos familiares em cuidar dos seus membros idosos está sendo afetada em virtude dessas mudanças estruturais nas famílias.

A Constituição de 1988 explicita que apenas na impossibilidade da família cuidar do idoso, instituições específicas devem ser consideradas uma alternativa de atendimento, quando a família realmente não tem condições ou habilidades necessárias para cuidar e prover a qualidade de vida que o idoso necessita, independente do grau de dependência. A Anvisa define ILPI como governamentais e não governamentais, de caráter residencial, destinadas ao domicílio de pessoas idosas, com ou sem suporte familiar, em condições de liberdade, dignidade e cidadania (RDC № 283

\footnotetext{
${ }^{1}$ Instituto Brasileiro de Geografía e Estatística
} 
de 26 de setembro de 2005).

Segundo Christophe (2007), a gerontologia e a geriatria apontam que o envelhecimento traz doenças crônicas, degenerativas e a diminuição da capacidade funcional, comprometendo a mobilidade e qualidade de vida do idoso. As definições de capacidade funcional seguem a Organização Mundial de Saúde - OMS, que as relaciona aos conceitos de autonomia, independência, qualidade e expectativa de vida saudável. $O$ autônomo é aquele que possui a capacidade de tomar decisões sobre a sua vida diária de acordo com a sua consciência. $O$ independente é o indivíduo que possui a capacidade de viver independente com alguma ou nenhuma ajuda. As atividades são classificadas pela OMS como AVDs (atividades da vida diária - tomar banho, comer, usar o banheiro, deambulação pelos cômodos, etc.) e AIVDs (atividades instrumentais da vida diária - trabalhos domésticos, fazer compras, preparar as refeições, etc.). A perda da capacidade funcional é determinada através de graus de dependência e pode ser gradual, definitiva ou reversível (Camarano e Mello, 2010).

A RDC no 283, de 26 de setembro de 2005, define três graus de dependência. O grau de dependência I são idosos independentes, mesmo que necessitem de equipamentos de autoajuda, o grau de dependência II são os idosos com dependência de até três atividades de autocuidado para a vida diária como a alimentação, a mobilidade, a higiene, sem comprometimento cognitivo ou com alteração cognitiva moderada, e o grau de dependência III são os idosos que necessitam de assistência em todas as AVDs e ou com comprometimento cognitivo.

Dados apresentados pelas Nações Unidas (2007), apontam que o envelhecimento da população pode afetar os sistemas de cuidados de saúde de duas maneiras: em primeiro lugar, o aumento do número total de casos de doenças crônicas e o maior número de pessoas com deficiência, exigindo novas habilidades de profissionais e trabalhadores da área de saúde, das indústrias, dos designers e da sociedade de um modo geral, haja vista que essas novas demandas exigirão a criação de estrutura através de serviços e produtos que garantam a qualidade de vida dos idosos e de seus cuidadores. Isso representa um enorme desafio para os países em desenvolvimento com populações que estão envelhecendo rapidamente. Em segundo lugar, a preocupação sobre a forma como a prestação de cuidados de longa duração serão oferecidos àqueles cujas condições de saúde são irreversíveis, e cuja família não dispõem de condições para garantir-lhes o necessário.

A pesquisa empreendida teve como objetivo estudar as questões acerca do envelhecimento populacional e o ato de cuidar nas ILPIs ${ }^{2}$, com foco na atividade de movimentação e transferência das pessoas com mobilidade reduzida no leito, observando as necessidades destes usuários frente as dificuldades no dia a dia, e a relação dos cuidadores, idosos e os equipamentos de assistência.

\section{Problematização}

Prestar cuidados aos idosos é um trabalho fisicamente exigente, muitas vezes necessitam de assistência para andar, tomar banho ou executar outras atividades do cotidiano. Em alguns casos, os pacientes são totalmente dependentes dos cuidadores para a realização das atividades da vida diária. Um exemplo é a elevação e movimentação manual, e outras tarefas que envolvem o reposicionamento, as quais estão associadas a um aumento do risco de lesões dos cuidadores, particularmente na região lombar.

Os fatores de risco que os cuidadores enfrentam são os seguintes (OSHA, 2009):

\footnotetext{
${ }^{2}$ Instituição de Longa Permanencia para Idosos
} 
- Força - a quantidade de esforço físico necessário para executar uma tarefa (como o levantamento de peso) ou para manter controle de equipamentos ou ferramentas;

- Repetição - realizando o mesmo movimento ou série de movimentos continuamente ou frequentemente;

- Posturas inadequadas - posições que colocam pressão sobre o corpo, como chegar acima da altura do ombro, ajoelhado, cócoras, inclinando-se sobre uma cama ou torcendo o dorso ao levantar.

De acordo com a American Nurse Association (ANA), as tarefas de movimentação de pacientes são reconhecidas como a principal causa de distúrbios osteomusculares entre os trabalhadores de enfermagem.

O desenvolvimento de tecnologias para movimentação de pacientes (equipamentos mecânicos) controla o risco ergonômico ocupacional, combinando as capacidades e limitações do corpo humano. Há um crescente número de instituições que incorporaram tecnologias de movimentação de pacientes com resultados positivos sobre a diminuição de lesões com o uso desses equipamentos, resultando em uma redução dos dias de trabalho perdidos e da rotatividade dos trabalhadores (ANA, 2015).

Dessa maneira, o problema de pesquisa foi como proporcionar por meio de um equipamento adequado, a movimentação e transferência de pessoas com mobilidade reduzida temporária ou permanente, gerada por problemas na estrutura ou funções do corpo, que acarretam desvios ou perdas da capacidade funcional que dificultam as atividades do dia-a-dia.

\section{Metodologia}

O design é um processo pelo qual buscam-se soluções criativas para facilitar e melhorar a qualidade de vida das pessoas, resolvendo problemas do cotidiano e humanizando as tecnologias. Segundo Brown (2010), as pessoas devem estar no centro desse processo para ajudá-las a articular as necessidades que às vezes nem sabem que tem. A imersão realizada pelo designer no contexto de uso, pode desenvolver novas habilidades, inspirando a criatividade e a inovação para a criação de produtos, estratégias e serviços de valor.

A pesquisa de campo realizada é qualitativa, de cunho exploratório e aplicada. Os métodos qualitativos ajudam os pesquisadores a desenvolver empatia, permitindo uma abordagem próxima ao usuário final. Também permite o questionamento de suposições para inspirar novas soluções. (Human Centered Design - HCD - Tool Kit, 2014).

A metodologia de desenvolvimento do projeto foi baseada no processo de Design Thinking desenvolvido por Hasso Platner Institute of Design at Stanford University. É uma ferramenta prática para a solução de problemas conhecidos ou desconhecidos, dividida em cinco etapas que podem acontecer de forma simultânea, conforme demonstradas no quadro 1. 
Quadro 1: Etapas do processo de Design Thinking

EMPATIA - Entender, observar, interagir e se relacionar com as pessoas para vivenciar a experiência de uso. Compreender através da perspectiva dos cuidadores as suas necessidades físicas e emocionais, como e porque as atividades são realizadas, o comportamento, e estabelecer relacionamentos, capturando o significado das experiências;

DEFINIÇÃO - É o processo de síntese das descobertas proveniente da fase de empatia e da pesquisa desk. É necessário processar tudo o que foi visto, observado e levantado para entender as necessidades e definir o problema de forma clara para direcionar o processo da criação da solução;

CRIAÇÃO - É a fase de geração de ideias, explorando e gerando uma ampla variedade de possíveis soluções;

PROTOTIPAGEM - É a transição da ideia para a forma física, transformando as propostas de solução do problema em artefatos concretos para experimentar e interagir fisicamente com a solução;

TESTE - Obter opiniões para refinar e validar a proposta selecionada.

Fonte: Adaptado pelo autor a partir de Hasso Plattner Institute of Design at Stanford.

Este artigo trata das etapas de Empatia e Definição que levou a estruturação dos requisitos para a o desenvolvimento de um equipamento para movimentar e transferir pessoas com mobilidade reduzida no leito.

$\mathrm{Na}$ etapa da empatia utilizou-se duas técnicas de pesquisa: Entrevista individual, técnica realizada por meio de um questionário estruturado e a interação social para obtenção das informações de interesse da pesquisa. Tem como objetivo a coleta de dados voltada à orientação acerca do que as pessoas sabem, creem, sentem e desejam a respeito do objeto de estudo (GIL, 2008); Observação do participante, técnica etnográfica qualitativa pela qual o pesquisador acompanha, observa e vivencia as atividades realizadas pelas pessoas no próprio contexto de uso. Desta maneira é possível interagir com os participantes da ação e com o ambiente. Esta técnica pode ser empregada nas fases iniciais da pesquisa e nas fases de prototipagem e testes. Estar no ambiente de trabalho ou doméstico das pessoas é delicado, é preciso ser discreto para que os participantes se sintam a vontade para serem autênticos na descrição das suas atividades e opiniões (MORAES \& SANTA ROSA, 2012).

$\mathrm{Na}$ etapa de definição foi realizada uma pesquisa desk exploratória em sites de empresas para o levantamento dos produtos disponíveis no mercado, e análise das características técnicas, ergonomia, usabilidade, pontos positivos e negativos, preço, etc. Também foi realizada a análise dos dados coletados na pesquisa de campo e sintetizados em uma proposta de valor.

\section{Empatia - Pesquisa de Campo}

A pesquisa de campo foi realizada em duas instituições de longa permanência para idosos: no Ventura Residence e na Casa de Repouso Pôr do Sol, ambas localizadas em Joinville-SC. Os relatos dos profissionais apontaram a falta de equipamentos adequados no mercado brasileiro para a transferência e movimentação de pacientes no leito, fazendo com que essa atividade seja realizada por dois cuidadores de forma manual, acarretando desgaste físico e afastamentos do trabalho. Na imersão e observação da atividade foi possível constatar que a movimentação e transferência de idosos no leito é uma atividade penosa com alto esforço físico. O cuidador assume posturas inadequadas, colocando pressão sobre o corpo e elevando o nível de esforço e o desgaste físico, 
podendo causar lesões musculares, desmotivando, frustrando, gerando afastamentos e comprometendo a qualidade da assistência.

A figura 1 demonstra o processo de transferência manual realizado pelos cuidadores evidenciando os riscos físicos para ambos: o paciente e os cuidadores.

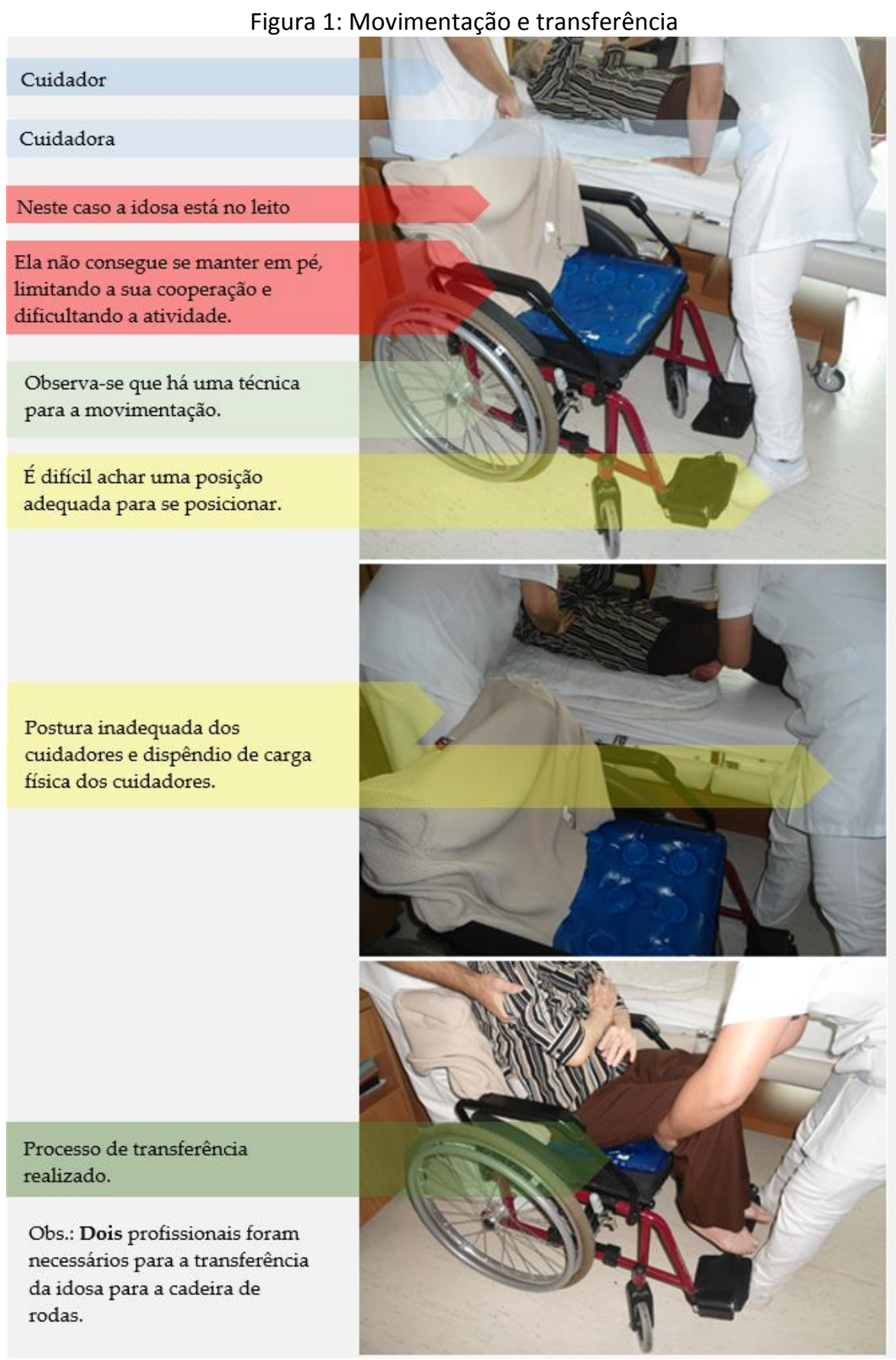

Fonte: Primária (2015)

As entrevistas e observações revelaram um cenário no qual há poucas opções de produtos para auxílio desta tarefa. Em alguns casos, os cuidadores preferem fazer a movimentação manual à utilizar os produtos existentes, pois alguns idosos negam-se à serem auxiliados pelos equipamentos porque se sentem constrangidos e inseguros. Mesmo quando recursos instrumentais necessários 
estão disponíveis, ainda há dificuldades na sua utilização para a movimentação e transferência.

Nas entrevistas com os profissionais da saúde, verificou-se que eles têm acesso a alguns equipamentos, porém inadequados, não atendendo plenamente as necessidades de uso. Bons produtos, com tecnologias aplicadas são caros e não estão disponíveis no Brasil.

Os equipamentos para a movimentação e transferência, na sua maioria, são importados, não sendo projetados para a realidade brasileira. O custo da importação pode inviabilizar a aquisição no Brasil. Desta maneira abre-se a oportunidade para o improviso, com soluções paliativas, sem os atributos necessários para garantir a eficácia, a dignidade, a segurança e o conforto físico dos cuidadores e idosos.

A pesquisa de campo proporcionou uma experiência e aprendizado profundo sobre as questões a cerca do ato de cuidar dos idosos nas instituições. A empatia na observação das dificuldades, frustrações, alegrias e os mais variados sentimentos foram reveladores nesse processo, e os problemas de transferência descritos na teoria foram comprovados na prática com a imersão nas ILPI's. Os dados coletados foram válidos para suportar o processo do design e estruturar os requisitos para o desenvolvimento de um equipamento para auxiliar a movimentação e transferência de pessoas com mobilidade no leito, melhorando as condições para realização desta tarefa.

\section{Definição - Análises e Proposta de valor}

Nesta etapa, por meio de uma pesquisa desk, foram investigadas algumas marcas que produzem equipamentos para a mobilidade, utilizado com pessoas que possuem a capacidade de cooperar como o cuidador. A empresa suíça Handicare fabrica o Return TM 700 (FIGURA 2), um modelo simples e funcional que garante a segurança tanto do paciente quanto do cuidador.

Figura 2: Equipamentos de assistência Handicare Return ${ }^{\mathrm{TM}} 700$
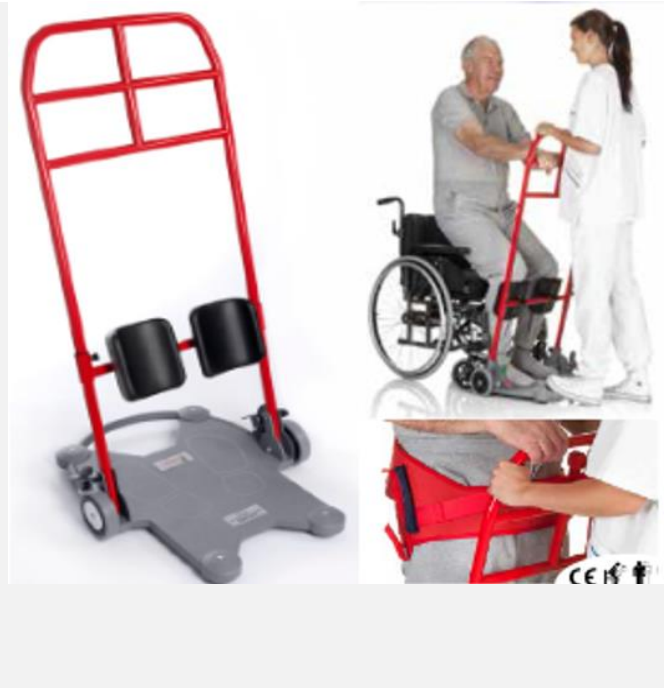

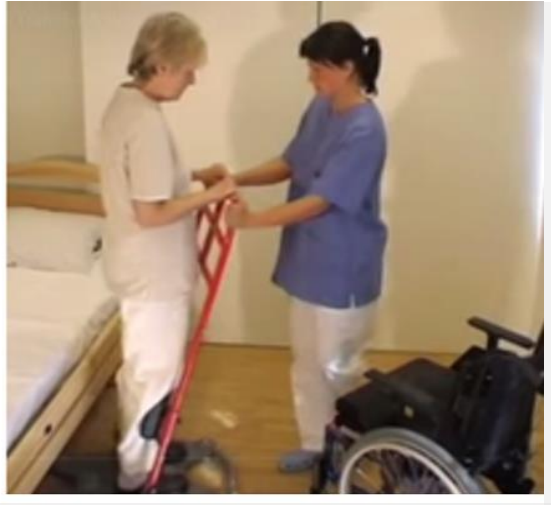

- Exemplo de utilização do equipamento para transferir a pessoa de uma posicão para outra.

Fonte: Handicare, Web, 2015.

O produto tem pontos positivos: compacto, fácil manutenção, estável, fácil manuseio, porém o preço $(\$ 1400,00)$ é incompatível com a realidade brasileira, sobretudo quando considerase ainda a importação e comercialização desse equipamento no Brasil. A pesquisa também foi realizada no mercado brasileiro e não foram encontradas empresas que produzam equipamento similar. 
Há um crescente número de instituições nos EUA que incorporaram esses equipamentos e os relatos sobre os resultados são positivos em relação a diminuição de lesões, resultando em uma redução dos dias de trabalho perdidos e da rotatividade dos cuidadores (ANA). Segundo Nelson (2001), os benefícios em longo prazo de um equipamento adequado para a movimentação e elevação de pacientes superam em muito os custos relacionados com acidentes de trabalho.

O quadro 2 demonstra de forma estruturada as fases da atividade de movimentação. Essa análise foi realizada por meio de recortes do vídeo de demonstração de utilização do equipamento Handicare Return ${ }^{\mathrm{TM}} 700$.

Quadro 2: Estrutura da tarefa

\begin{tabular}{|c|c|}
\hline $\begin{array}{l}1 \text { - Posicionar o } \\
\text { paciente na posição } \\
\text { sentada na cama }\end{array}$ & O cuidador ajuda se necessário pessoa a sentar na borda da cama; \\
\hline $\begin{array}{l}2 \text { - Posicionar o } \\
\text { equipamento }\end{array}$ & $\begin{array}{l}\text { O cuidador posiciona o equipamento e o trava, auxilia a pessoa à apoiar os pés na base do } \\
\text { produto, a segurar-se e ajusta o apoio da perna; }\end{array}$ \\
\hline $\begin{array}{l}3 \text { - Colocar o } \\
\text { paciente em pé no } \\
\text { equipamento }\end{array}$ & $\begin{array}{l}\text { Neste momento a pessoa coopera com a atividade. A pessoa segura-se no equipamento e } \\
\text { utiliza a força das pernas e dos braços para se colocar em pé, com ou nenhuma ajuda do } \\
\text { cuidador. O cuidador posiciona-se para dar estabilidade ao equipamento. O equipamento } \\
\text { deve prover a estabilidade e segurança; }\end{array}$ \\
\hline 4 - Girar & $\begin{array}{l}\text { O paciente está em pé segurando-se no equipamento. O cuidador rotaciona o } \\
\text { equipamento manualmente para direciona-lo à posição desejada. Quanto menor o espaço } \\
\text { maior será a dificuldade; }\end{array}$ \\
\hline $\begin{array}{l}5 \text { - Movimentar e } \\
\text { direcionar }\end{array}$ & $\begin{array}{l}\text { O paciente está em pé segurando-se no equipamento. O cuidador movimenta } \\
\text { equipamento empurrando-o e direcionando manualmente. É necessário que o cuidador } \\
\text { garanta que o paciente esteja seguro. Se ele não conseguir permanecer em pé por muito } \\
\text { tempo o equipamento pode prover uma forma de apoio segura para uma posição } \\
\text { sentado ou semi sentado; }\end{array}$ \\
\hline $\begin{array}{l}6 \text { - Posicionar o } \\
\text { equipamento }\end{array}$ & $\begin{array}{l}\text { O cuidador posiciona o equipamento em frente da cadeira de rodas, do vaso sanitário, } \\
\text { etc. Travando-o na posição para dar estabilidade; }\end{array}$ \\
\hline $\begin{array}{l}7 \text { - Sair do } \\
\text { equipamento }\end{array}$ & $\begin{array}{l}\text { O cuidador posiciona o equipamento e o trava, orienta e auxilia a pessoa a sair do } \\
\text { equipamento e se sentar. A pessoa segura-se no equipamento e utiliza a força das pernas } \\
\text { e dos braços para sentar-se com ou nenhuma ajuda do cuidador. O cuidador posiciona-se } \\
\text { para dar estabilidade ao equipamento. O equipamento deve prover a estabilidade e } \\
\text { segurança; }\end{array}$ \\
\hline
\end{tabular}

Fonte: Primária (2015).

Os passos mais críticos identificados são o 3, 4, 5 e 6, influenciando diretamente na experiência de cuidado. Nessas fases há uma interação maior entre o equipamento, o paciente e o cuidador. É possível que nestas fases os riscos físicos e emocionais sejam mais evidentes. As análises apresentam oportunidades de inovação por meio do design, a fim de assegurar uma experiência de cuidado positiva nesta atividade.

A solução deve ser baseada nas necessidades dos envolvidos neste processo, para evitar os problemas físicos e emocionais gerados. Este processo foi sumarizado no diagrama de causas e efeitos apresentado na figura 3. 
Figura 3: Diagrama de Causas e efeitos

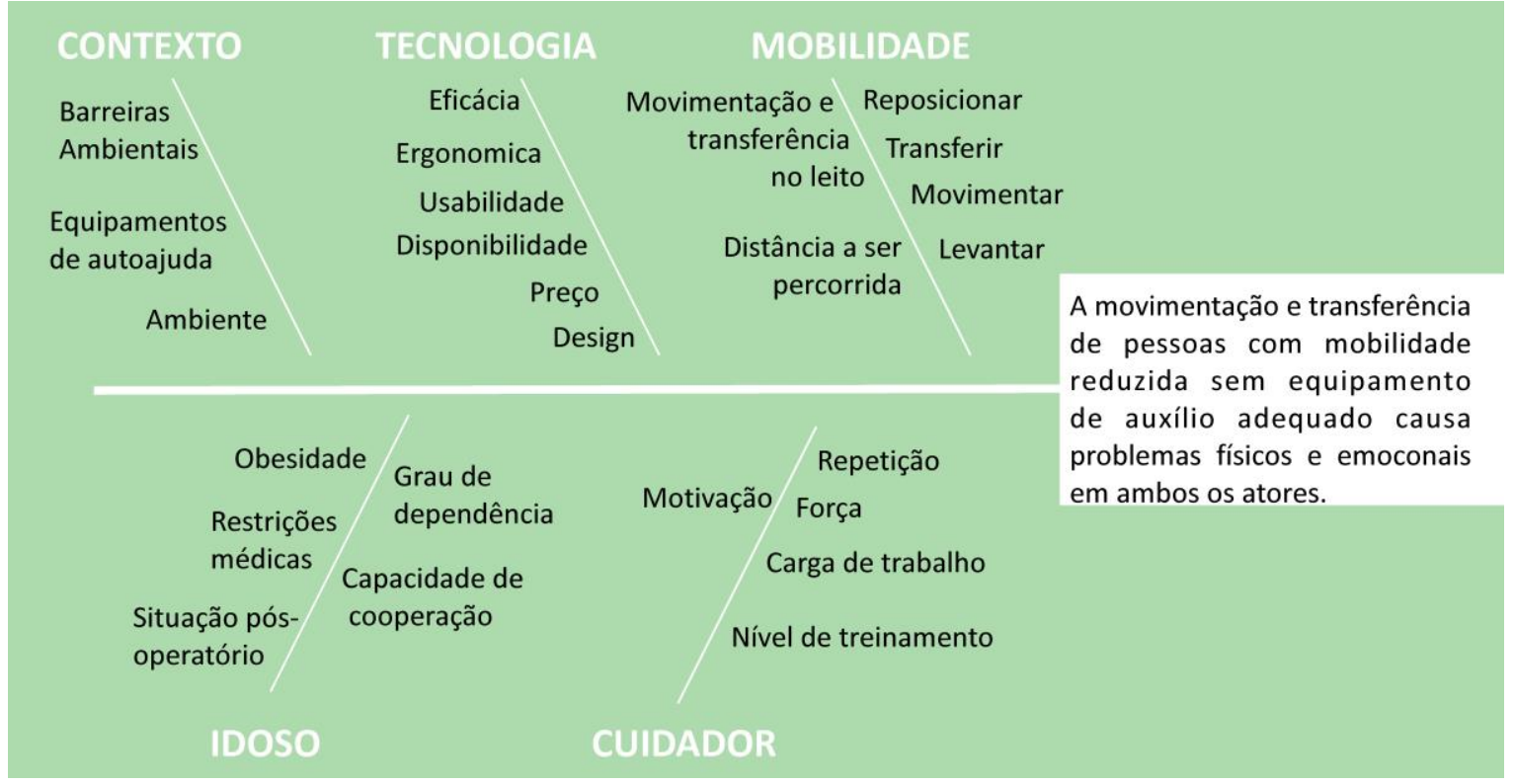

Fonte: Primária (2015)

Para sintetizar os dados coletados e ter uma visão sistêmica sobre todos os fatores que influenciam a movimentação de pessoas com mobilidade reduzida no leito, tanto na perspectiva do cuidador como na do idoso, foi utilizada a ferramenta do Mapa de Valor (THE VALUE PROPOSITION CANVAS, web 2015). Esta ferramenta traz no lado direito o mapa de empatia e no lado esquerdo a proposta de valor com os atributos e benefícios sugeridos para a solução do problema.

Para amenizar os problemas físicos dos cuidadores, garantir a segurança e evitar o constrangimento do idoso, foi estruturada uma proposta de valor para atender as necessidades de ambos os atores. A figura 4 demonstra uma visão sintética e empática acerca do problema em que relaciona, no lado direito, todas as atividades que são realizadas, as dificuldades e consequências negativas geradas e as necessidades e desejos dos cuidadores. No lado esquerdo está a proposta de valor que o design pode oferecer para solucionar o problema, entregando benefícios que amenizem as dificuldades e atributos que atendem as necessidades e desejos dos cuidadores. 
Figura 4: Proposta de valor para os cuidadores

DESIGN - Proposta de valor

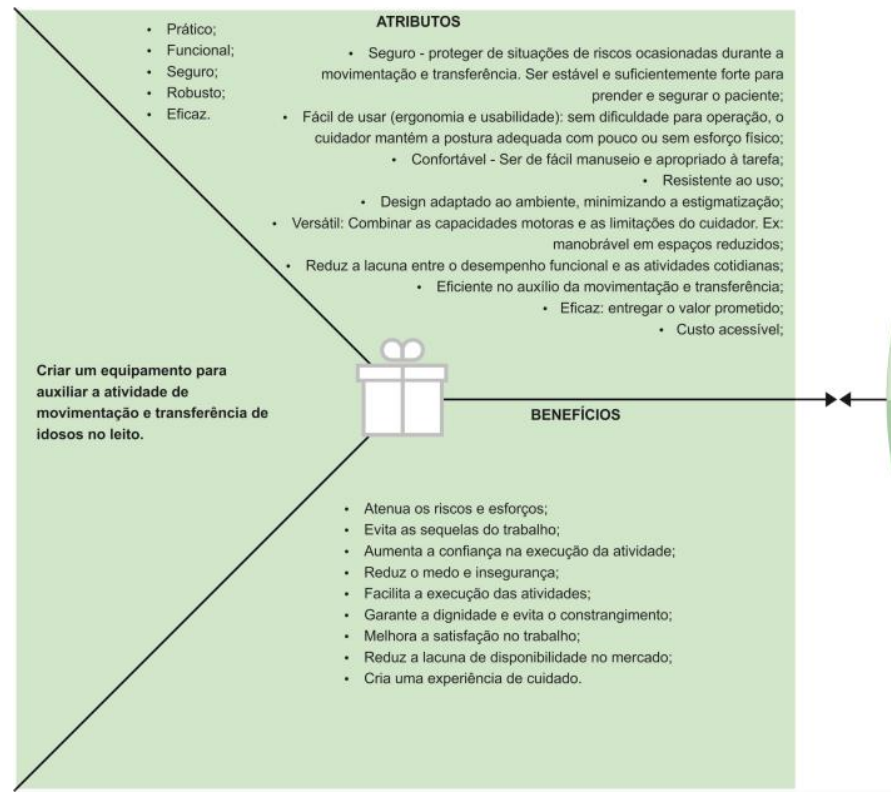

Fonte: Primária (2015)

A figura 5 demonstra a proposta de valor para os idosos, que possuem limitações e constrangimentos com a atividade de movimentação e transferência. A proposta é a mesma para ambos, mas com objetivos distintos, pois o valor percebido será diferente para os dois atores.

Figura 5: Proposta de valor para o idoso.

DESIGN - Proposta de valor

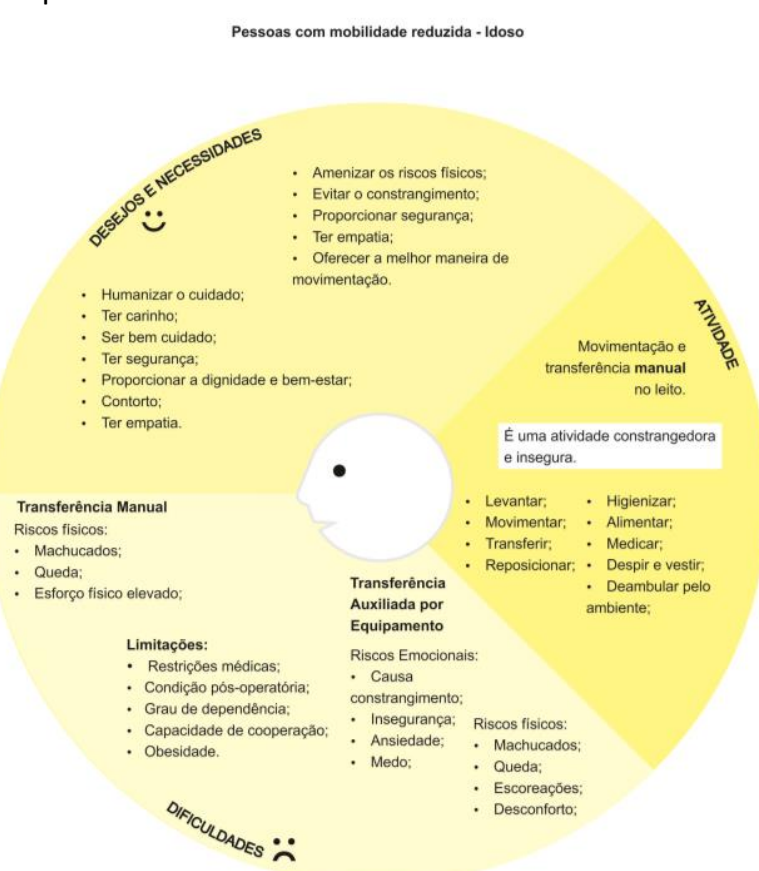

Fonte: Primária (2015).

A proposta de valor serviu de base para a elaboração dos requisitos necessários e desejáveis, a partir 
dos atributos e benefícios pretendidos no desenvolvimento de um equipamento de auxilio que garanta o bem-estar tanto do cuidador quanto do idoso.

\section{Requisitos}

Os requisitos foram estruturados no sentido de garantir que os desejos e necessidades dos usuários sejam atendidos e as dificuldades amenizadas durante o processo de movimentação e transferência de pessoas com mobilidade reduzida no leito. Considera-se que o cuidado e o cuidador possuem necessidades físicas e emocionais distintas e estarão envolvidos na mesma atividade, utilizando o mesmo equipamento, portanto, os requisitos deverão atender a ambos, Ihes garantindo de forma simultânea, o conforto e o bem-estar.

Segundo Nelson (2001), alguns requisitos são importantes na seleção dos equipamentos para a movimentação e transferência dos pacientes:

1. Ser apropriado para a tarefa que está sendo realizada;

2. Prover segurança para o paciente e para o profissional da saúde - ser estável e suficientemente forte para prender e segurar o paciente, e permitir que o prestador de cuidados mantenha a postura adequada;

3. Ser confortável para o paciente - não deve produzir ou intensificar a dor e não deve gerar hematomas;

4. Ser de fácil manuseio;

5. Ser eficiente;

6. A manutenção deve ser mínima;

7. Deve ser de fácil armazenamento;

8. O dispositivo deve ser manobrável em um espaço de trabalho confinado;

9. O dispositivo deve ser versátil;

10. O dispositivo deve ser de fácil limpeza;

11. Deve ter custo acessível.

Os dados levantados na etapas de empatia e definição, assim como os requisitos descritos por Nelson (2001), embasam os requisitos para o desenvolvimento de um equipamento que possa fornecer mobilidade suportada para auxiliar os cuidadores a movimentar e transferir pessoas com mobilidade reduzida no leito, conforme quadro 3. 
Quadro 3: Requisitos

Requisitos de projeto

Mobilidade/

Usabilidade

Experiência positiva no ato de cuidar

\section{Estéticos}

Ergonômicos

funcionais
Objetivos

Classificação

Aliviar o esforço físico sobre o cuidador.

Favorecer o paciente a ficar em pé sem ou com pouca assistência do cuidador;

Prover apoio adequado, o equipamento deve ser estável suficiente para dar segurança para ambos os atores;

Ser confortável para o paciente;

Ser manobrável em espaços reduzidos;

Estar apto a transportar o paciente sem a necessidade de cadeira de rodas;

Ter as dimensões adaptadas ao cuidador e ao paciente;

Ser adaptável: ter regulagens para se adaptar aos usuários;

Prover as affordances necessárias para o uso do equipamento;

Ser possível transferir a pessoa para a cadeira de rodas, para poltronas e cadeiras;

Ser possível transferir a pessoa para a o vaso sanitário.

Minimizar os efeitos emocionais negativos da atividade de Necessário movimentação e transferência;

Estimular o paciente a participar da atividade;

Promover a dignidade e a independência do paciente tanto quanto for possível, proporcionando seu bem-estar;

Promover a interação entre o cuidador e o paciente durante a atividade pelo contato visual e atenção mútua.

Estética atrativa e amigável expressas nos aspectos de conforto e Necessário segurança, sendo convidativo e sem estigmas.

Utilizar cores adequadas: representar saúde e disposição;

Formas suaves;

Ter assento para o idoso: posição semi-sentada ou sentada.

Prover encosto para as pernas ajustável;

Pegas e empunhaduras adequadas;

Suportar 200 kg;

Ser de fácil limpeza;

Ser de fácil armazenamento;

Ser dobrável;

Prover base para apoio dos pés antiderrapante;

Dimensão da base adequada ao idoso;

Ter freios para travamento do equipamento;
Desejável

Necessário

Necessário

Necessário

Necessário

Desejável

Necessário

Necessário

Necessário

Necessário

Necessário

Necessário

Necessário

Necessário

Necessário Desejável

Necessário

Necessário

Necessário

Necessário

Necessário

Desejável

Necessário

Necessário

Necessário

Necessário 


\begin{tabular}{|c|c|c|}
\hline & Ter ajustes para diversos percentis ergonômicos; & Necessário \\
\hline & Prover estrutura de apoio com diferentes posições de pega; & Desejável \\
\hline \multirow{4}{*}{ Técnicos } & Ser durável; & Necessário \\
\hline & Ser de fácil manutenção; & Necessário \\
\hline & Girar no próprio eixo; & Desejável \\
\hline & Ter sistema de dobra; & Desejável \\
\hline \multirow{3}{*}{ Materiais } & Tubos de aço para estrutura; & Necessário \\
\hline & Base em Nylon fibra ou ABS; & Desejável \\
\hline & Pegas e empunhaduras em polímero ou borracha; & Desejável \\
\hline Preço & Ter custo acessível & Desejável \\
\hline
\end{tabular}

Fonte: Primária (2015).

Acredita-se que os requisitos podem direcionar o projeto e o desenvolvimento de um equipamento de acordo com a realidade brasileira, provendo conforto e dignidade para as pessoas envolvidas nessa atividade.

\section{CONSIDERAÇÕES FINAIS}

A pesquisa empreendida proporcionou um conhecimento sobre o ato de cuidar dentro das ILPI's e os problemas enfrentados pelos cuidadores e idosos na execução das tarefas do dia-a-dia, destacando-se a atividade de movimentação e transferência de pessoas com mobilidade reduzida.

A metodologia utilizada foi essencial para o planejamento da pesquisa e a convergência dos dados. Destaca-se a importância da empatia no processo de design para interagir e descobrir as necessidades e desejos das pessoas. Estar próximo e compartilhar as dificuldades muda o olhar sobre o problema, trazendo motivação e experiência para a solução do mesmo. Ao acompanhar e observar os cuidadores na realização das tarefas, foi possível perceber as grandes dificuldades encontradas. As improvisações criadas para atender às necessidades das pessoas que estão sob cuidado, abre um campo ainda inexplorado pelos designers para oferecer soluções eficazes com um custo acessível.

A pesquisa também contribuiu para o estudo no campo do design em uma área ainda pouco explorada, mostrando as oportunidades latentes na área médica, principalmente as de cuidado e assistência às atividades da vida diária das pessoas com mobilidade reduzida, representadas aqui pelos idosos. Este campo de estudo é amplo e pouco explorado no Brasil, e ainda carente de produtos bem projetados e eficazes, baseados nos princípios de design e usabilidade.

Alex Ross (WHO, 2013) salienta que em uma era sem precedentes de avanços tecnológicos, apesar da abundância de tecnologias disponíveis para a área da saúde, ainda há enormes lacunas na disponibilidade de tecnologias com preço acessível, segura, eficaz e apropriada para o profissional da saúde. Ao aproximar o design desse problema relatado, pode-se buscar soluções que atendam as necessidades dos pacientes e cuidadores, que seja viável, factível e desejável.

O aprendizado sobre o contexto do envelhecimento, a imersão nas ILPIs, a definição do problema de pesquisa e a proposta de valor, contribuíram para a definição de uma lista de requisitos fundamentais para conceber um equipamento para movimentar e transferir pessoas com mobilidade reduzida no leito. 


\section{Referências}

ANA (Amarican Nurses Association). Handle With Care Fact Sheet. Disponivel em:

http://www.nursingworld.org/MainMenuCategories/WorkplaceSafety/Healthy-Work-

Environment/SafePatient/Resources/FactSheet.html. Acesso em: 20/06/2015;

BROWN, Tim. Design Thinking. 3a ed. Rio de Janeiro: Elsevier, 2010;

CAMARANO, Ana Amélia; Kanso, Solange. As Instituições de longa permanência no Brasil. Revista

Brasileira de Estudos Populacionais: Rio de Janeiro, 2010. Disponível em:

http://www.scielo.br/pdf/rbepop/v27n1/14.pdf. Acesso em 5/06/2015;

CAMARANO, Ana Amélia; KANSO, Solange; MELLO, Juliana Leitão. Como vive o idoso brasileiro?

In: CAMARANO, A. A. (Org.). Cuidados de longa duração para a população Idosa: um novo risco assumido? Rio de Janeiro: Instituto de Pesquisa Econômica Aplicada - IPEA, 2010. p. 25-73.

CHRISTOPHE, Micheline. Instituições de longa permanência para o idoso no Brasil: uma opção de longa duração? 2007. Dissertação de Mestrado - Escola Nacional de Ciências Estatístticas. Rio de Janeiro;

THE VALUE PROPOSITION CANVAS. Copyright Strategyzer AG. Disponível em: http://www.businessmodelgeneration.com/canvas/vpc. Acesso em: 20/05/2015;

NELSON, Andrey; BAPTISTE, Andrea. Evidence-based Practices For Fafe Patient Handling and Movement. Ana Periodicals, Volume 9, 2004. Disponível em:

http://www.nursingworld.org/MainMenuCategories/ANAMarketplace/ANAPeriodicals/OJIN/Table ofContents/Volume92004/No3Sept04/EvidenceBasedPractices.aspx. Acesso em: 05/06/2015

NELSON, A. L.Patient Care Ergonomics Resource Guide: Safe Patient Handling and Movement. Veterans Adminstration Patient Safety Center of Inquiry, 2001. Revisão: 31/08/2005. Disponível em: http://www.visn8.va.gov/patientsafetycenter/resguide/ErgoGuidePtOne.pdf. Acesso em: Acesso em 19/06/2015;

HCD. Kit de Ferramentas. 2 ed: Ideo. Disponível em:

http://www.ideo.com/images/uploads/hcd toolkit/HCD Portuguese.pdf. Acesso em 15/08/2004; PLATTNER, Hasso. An Introduction to Design Thinking. Process Guide. Institute of Design at Stanford. Disponível em:

https://dschool.stanford.edu/sandbox/groups/designresources/wiki/36873/attachments/74b3d/ ModeGuideBOOTCAMP2010L.pdf?sessionID=9a5d0a2a0cd5fb6c26a567b2636b19513b76d0f4.

Acesso em: 15/05/2015; 